\title{
The potential of mouse skin-derived precursors to differentiate into mesenchymal and neural lineages and their application to osteogenic induction in vivo
}

\author{
HYUN KI KANG $^{1}$, SEUNG-KI MIN ${ }^{2}$, SUNG YOUN JUNG ${ }^{1}$, KYOUNGSUK JUNG ${ }^{3}$, \\ DA HYUN JANG ${ }^{1}$, O BOK KIM ${ }^{1}$, GAE-SIG CHUN ${ }^{4}$, ZANG HEE LEE ${ }^{3}$ and BYUNG-MOO MIN ${ }^{1}$
}

\author{
${ }^{1}$ Department of Oral Biochemistry and Program in Cancer and Developmental Biology and DRI, Seoul National University \\ School of Dentistry; ${ }^{2}$ Department of Oral and Maxillofacial Surgery, Seoul National University School of Dentistry; \\ ${ }^{3}$ Department of Cell and Developmental Biology, Seoul National University School of Dentistry, Seoul 110-749; \\ ${ }^{4}$ Department of Oral Physiology, Dankook University School of Dentistry, Cheonan 330-714, Republic of Korea
}

Received June 29, 2011; Accepted July 27, 2011

DOI: 10.3892/ijmm.2011.785

\begin{abstract}
Although previous studies indicate that skin-derived precursors (SKPs) are multipotent dermal precursors that share similarities with neural crest stem cells (NCSCs), a shared ability for multilineage differentiation toward neural crest lineages between SKPs and NCSCs has not been fully demonstrated. Here, we report the derivation of SKPs from adult mouse skin and their directed multilineage differentiation toward neural crest lineages. Under controlled in vitro conditions, mouse SKPs were propagated and directed toward peripheral nervous system lineages such as peripheral neurons and Schwann cells, and mesenchymal lineages, such as osteogenic, chondrogenic, adipogenic, and smooth muscle cells. To ask if SKPs could generate these same lineages in vivo, a mixture of SKP-derived
\end{abstract}

Correspondence to: Dr Byung-Moo Min, Department of Oral Biochemistry and Program in Cancer and Developmental Biology, Seoul National University School of Dentistry, 28 Yeonkun-Dong, Chongno-Ku, Seoul 110-749, Republic of Korea

E-mail:bmmin@snu.ac.kr

Abbreviations: SKPs, skin-derived precursors; NCSCs, neural crest stem cells; MSCs, mesenchymal stem cells; HA, hydroxyapatite; TCP, tricalcium phosphate; CMF-HBSS, calcium- and magnesium-free Hanks' balanced salt solution; bFGF, basic fibroblast growth factor; BDNF, brain-derived neurotrophic factor; NT3, neurotrophin-3; dbcAMP, dibutyryl cyclic AMP; $\alpha$-MEM, $\alpha$-minimal essential medium; GFAP, glial fibrillary acidic protein; SMA $\alpha$, smooth muscle actin $\alpha$; micro-CT, micro-computed tomography; H\&E, hematoxylin and eosin; ALP, alkaline phosphatase; BSP, bone sialoprotein; ATF3, activating transcription factor 3; Col2 $\alpha 1$, collagen type II $\alpha 1$; Ihh, Indian hedgehog; Sox5, SRY-box containing gene 5; PPAR $\gamma$, peroxisome proliferation-activated receptor $\gamma$; LPL, lipoprotein lipase; $\mathrm{C} / \mathrm{EBP} \alpha, \mathrm{CCAAT} / \mathrm{enhancer}$ binding protein $\alpha$

Key words: mouse skin, skin-derived precursors, neural differentiation, mesenchymal differentiation, osteogenic induction mesenchymal stem cells and hydroxyapatite/tricalcium phosphate was transplanted into the rat calvarial defects. Over the ensuing 4 weeks, we observed formation of osteogenic structure in the calvarial defect without any evidence of teratomas. These findings demonstrate the multipotency of adult mouse SKPs to differentiate into neural crest lineages. In addition, SKP-derived mesenchymal stem cells represent an accessible, potentially autologous source of precursor cells for tissue-engineered bone repair.

\section{Introduction}

Stem cells/precursors provide an in vitro model to study a potential source of specialized cells for use in regenerative medicine (1). The most obvious therapeutic use of such multipotent adult human precursors is for cell transplantation and replacement. Although adult stem cells were previously believed to have a limited differentiating potential, recent evidence indicates that various types of cells can be generated from adult stem cells derived from various tissues, such as bone marrow, fat, and skin (2-4). A growing number of studies have focused on the possibility that adult stem cells are a realistic therapeutic alternative to embryonic stem cells, because several adult stem cell types show a surprisingly diverse differentiation repertoire $(5,6)$.

Recently, multipotent skin-derived precursors (SKPs) were isolated from the dermis of embryonic, neonatal, and adult rodent skin, as well as from adult human skin, which is a highly accessible tissue source (2). SKPs have properties similar to embryonic neural crest stem cells (NCSCs) $(7,8)$. SKPs differentiate into peripheral neural cells, including Schwann cells $(9,10)$ and catecholaminergic neurons $(11)$, as well as mesenchymally-derived smooth muscle cells, adipocytes $(2,12)$, osteocytes, and chondrocytes (6). SKPs isolated from rodent and mammalian skins can form spheres in serum-free medium and differentiate into both neural and mesodermal progeny, including cell types never found in skin, such as neurons. SKPs represent an embryonic neural crest-related precursor cell that arises in skin during embryogenesis and persists in lower 
numbers into adulthood (7). Mesenchymal tissues of the facial region and upper trunk in mammals are known to develop from cranial neural crest cells. The role of neural crest cells in mesenchymal tissues has been demonstrated in several studies with the chick-quail chimera system, developing transgenic mice, and human embryonic stem cell-derived neural crest cells (13-15). Multipotent adult SKPs offer the potential to treat the injured nervous system (9) and could also be useful for cell replacement therapy for mesenchymal tissue/structures. SKPs can be isolated and expanded from adult human skin (12), thereby representing a potentially autologous source of cells. Although many efforts have been made, it remains to be seen whether SKPs can differentiate into therapeutically useful mesenchymal cell types.

Due to ethical considerations related to the use of fetal tissues and the somewhat laborious and painful procedure associated with bone marrow aspiration, it would be ideal to have an easily accessible source of adult stem cells, such as subcutaneous adipose tissue or skin, in adult subjects. Although SKP-derived mesenchymal stem cells (MSCs) can differentiate into morphologically discernable cell types, few studies have demonstrated that SKP-derived MSCs differentiated in vitro show multipotency to differentiate into lineages of mesenchymal tissues, including bone, cartilage, fat, and muscle. Because SKPs are known to share similarities with NCSCs, we evaluated the possibility that SKPs derived from adult mouse skin could be directed to develop into mesenchymal and peripheral nervous system lineages. We also assayed that SKP-derived MSCs can promote osteogenic induction in vivo. In this study, the effect of a mixture of SKP-derived MSCs and hydroxyapatite (HA)/ tricalcium phosphate (TCP) was examined in a rat calvarial defect model.

\section{Materials and methods}

Animals and materials. Six-week-old male Sprague-Dawley rats (body weight 180-200 g) and 6- to 7-week-old female C57/BL6 mice (20-25 g) were purchased from Orient Bio Inc. (Seongnam, Korea). Animals were maintained in plastic cages in a room with 21-h day/night cycles at an ambient temperature of $21^{\circ} \mathrm{C}$ with ad libitum access to water and a standard laboratory pellet diet. All animal procedures were reviewed and approved by the animal care committee of the Institute of Laboratory Animal Resources of Seoul National University. Beschitin $\mathrm{W}^{\circledR}$, a commercial nonwoven-type chitin microfiber, was purchased from Unitika Co. (Osaka, Japan). Porous HA/ TCP was purchased from Zimmer (Warsaw, IN, USA).

Primary cell culture and sphere formation. SKPs were isolated as previously described $(2,7)$ from 6 to 7 -week-old C57/BL6 mice (Orient Bio Inc.). Briefly, skin samples composed of epidermis and dermis were dissected, cut into small pieces, and digested in $0.1 \%$ Trypsin-EDTA in calcium- and magnesiumfree Hanks' balanced salt solution (CMF-HBSS; Invitrogen, Carlsbad, CA, USA) for $60 \mathrm{~min}$ at $37^{\circ} \mathrm{C}$. Partially digested skin pieces were mechanically dissociated and filtered through a 40- $\mu \mathrm{m}$ cell strainer (BD Biosciences, Bedford, MA, USA). Filtered cells were washed, resuspended, and plated on 35-mm culture dishes. Cells were grown in DMEM/F12 (vol/vol, 1:1) medium supplemented with 1X B-27 supplement (Invitrogen),
$20 \mathrm{ng} / \mathrm{ml}$ basic fibroblast growth factor (bFGF), and $20 \mathrm{ng} /$ ml EGF (PeproTech, Rocky Hill, NJ, USA) for 1 week, and growth factors were added to the medium every 2 days without medium change. For serial sphere formation assays, subculture was done once a week for three weeks after dissociation of spheres with accutase (Innovative Cell Technologies, San Diego, CA, USA).

Cell differentiation. For directed differentiation of skinderived sphere-forming cells toward peripheral nerve or Schwann cells, cells were dissociated with accutase and plated at $5-20 \times 10^{3}$ cells on polyornithine $(15 \mu \mathrm{g} / \mathrm{ml}) / \mathrm{laminin}$ $(1 \mu \mathrm{g} / \mathrm{ml})$-coated culture dishes. Cultures were established in serum-free DMEM/F12 medium supplemented with $50 \mathrm{ng} / \mathrm{ml}$ brain-derived neurotrophic factor (BDNF), $10 \mathrm{ng} / \mathrm{ml}$ neurotrophin-3 (NT3), and $50 \mathrm{ng} / \mathrm{ml} \mathrm{NGF} \mathrm{(PeproTech)} \mathrm{(peripheral}$ nerve cells) or $10 \mathrm{mM}$ dibutyryl cyclic AMP (dbcAMP; SigmaAldrich, St. Louis, MO, USA), $10 \mathrm{ng} / \mathrm{ml}$ bFGF, and $20 \mathrm{ng} / \mathrm{ml}$ neuregulin (PeproTech) (Schwann cells). The medium was changed every two days, and cultures were maintained for two weeks without passage.

For mesenchymal differentiation, skin-derived spheres were dissociated with accutase, resuspended in $1 \mathrm{ml}$ DMEM/F12 medium, supplemented with $20 \mathrm{ng} / \mathrm{ml} \mathrm{EGF,} 20 \mathrm{ng} / \mathrm{ml} \mathrm{bFGF}$, and $1 \mathrm{X} \mathrm{B}-27$, and plated on polyornithine $(15 \mu \mathrm{g} / \mathrm{ml}) / \mathrm{laminin}$ $(1 \mu \mathrm{g} / \mathrm{ml}) /$ fibronectin $(10 \mathrm{ng} / \mathrm{ml})$-coated $100-\mathrm{mm}$ culture dishes. After 4 h, 9 ml DMEM/F12 medium, supplemented with EGF, bFGF, and B-27, were added. After $24 \mathrm{~h}$ of culture, medium was changed with $\alpha$-minimal essential medium ( $\alpha$-MEM) containing $10 \%$ FBS without growth factors. Attached cells were subcultured at every $80 \%$ confluence, and third passage cells were used in the described experiments as SKP-derived mesenchymal cells. For osteogenic differentiation, SKP-derived mesenchymal cells were plated at a low density $\left(4.0 \times 10^{3}\right.$ cells/24-well) and cultured in $\alpha$-MEM supplemented with $10 \mathrm{mM} \beta$-glycerol phosphate, $10 \mu \mathrm{M}$ dexamethasone, $200 \mu \mathrm{M}$ ascorbic acid, and $10 \%$ FBS for 2 weeks. Medium was changed every two days, and the cultures were maintained for two weeks without passage.

For chondrogenic differentiation, SKP-derived mesenchymal cells were resuspended in $\alpha$-MEM supplemented with $10 \mathrm{ng} / \mathrm{ml}$ TGF- $\beta, 200 \mu \mathrm{M}$ ascorbic acid, and 10\% FBS. For preparation of each pellet, aliquots of $1.0 \times 10^{6}$ cells in $5 \mathrm{ml}$ defined medium were spun down at $390 \times \mathrm{g}$ for $3 \mathrm{~min}$ in $15-\mathrm{ml}$ polypropylene conical tubes. Pellets were cultivated for 4 weeks at $37^{\circ} \mathrm{C}$ by changing the medium every two days. For adipogenic differentiation, SKP-derived mesenchymal cells were plated at $2.5 \times 10^{4}$ cells per well of a 24 -well plate and cultured in $\alpha$-MEM supplemented with $0.5 \mathrm{mM} 1$-methyl3-isobutylxanthine, $1 \mathrm{mM}$ dexamethasone, $10 \mu \mathrm{g} / \mathrm{ml}$ insulin, $50 \mathrm{mM}$ indomethacin, and 10\% FBS. Medium was changed every two days, and the cultures were maintained for four weeks without passage. For myogenic differentiation, SKP-derived mesenchymal cells were cultured in $\alpha$-MEM supplemented with $10 \%$ FBS until the cells reached $90 \%$ confluence. Cells were then subcultured at every $90 \%$ confluence for six weeks.

Histological staining. Histological staining of osteogenic cells was performed, as described previously (6). Briefly, to visualize mineral deposits, cells were fixed with ice-cold $95 \%$ ethanol for $30 \mathrm{~min}$ at $-20^{\circ} \mathrm{C}$ and stained with alizarin red $\mathrm{S}$ solution 
(40 mM alizarin red $\mathrm{S}$ in double-distilled $\mathrm{H}_{2} \mathrm{O}, \mathrm{pH}$ 4.2) for $1 \mathrm{~h}$. The stained cells were washed with double-distilled $\mathrm{H}_{2} \mathrm{O}$ five times and then rinsed with PBS for 15 min. For chondrocyte proteoglycans, chondrocyte pellets were washed with PBS, fixed in $10 \%$ formalin for 5 min, embedded with Tissue-Tek ${ }^{\circledR}$ O.C.T. Compound (Sakura Finetek, Torrance, CA, USA), and then cut into $5-\mu \mathrm{m}$ sections using a cryostat (Leica CM3050 S; Leica Microsystems Nussloch $\mathrm{GmbH}$, NuBloch, Germany). Sections were hydrated, incubated in $3 \%$ acetic acid for $3 \mathrm{~min}$, stained with alcian blue $8 \mathrm{GX}$ solution $(1 \%$ alcian blue $8 \mathrm{GX}$ in $3 \%$ glacial acetic acid, $\mathrm{pH} 2.5$ ) for $30 \mathrm{~min}$, rinsed with running water for $2 \mathrm{~min}$, and then photographed. To detect adipocytes, cells were washed with PBS, fixed in $10 \%$ formalin for $5 \mathrm{~min}$, washed with $60 \%$ isopropanol, completely dried, stained with oil red $\mathrm{O}$ solution ( $0.42 \%$ oil red $\mathrm{O}$ in $60 \%$ isopropanol) for $10 \mathrm{~min}$, rinsed with double-distilled $\mathrm{H}_{2} \mathrm{O}$ four times, and then photographed.

Immunocytochemistry. SKPs were differentiated toward peripheral nerve or Schwann cells on glass slide chambers for two weeks, as described elsewhere. Differentiated smooth muscle cells were also cultured on glass slide chambers in $\alpha$-MEM supplemented with $10 \%$ FBS for 2 days. Cells were fixed with $2 \%$ paraformaldehyde for $30 \mathrm{~min}$ at room temperature and then permeabilized with $0.1 \%$ Triton $\mathrm{X}-100$. After blocking with PBS containing 1\% BSA for $60 \mathrm{~min}$, cells were incubated with primary antibodies to TuJ1 (1:200; R\&D Systems, Minneapolis, MN, USA), peripherin (1:50; Santa Cruz Biotechnology, Santa Cruz, CA, USA), glial fibrillary acidic protein (GFAP) (1:500; Chemicon, Temecula, CA, USA), S100 $\beta$ (1:100), smooth muscle actin $\alpha$ (SMA $\alpha)(1: 100$; Sigma-Aldrich), and desmin (1:100; Dako, Glostrup, Denmark) for $1 \mathrm{~h}$ at room temperature and then stained with secondary antibodies (FITC-conjugated goat anti-mouse IgG and Cy3-conjugated goat anti-rabbit IgG). Nuclei were counterstained with DAPI. The images were observed and recorded using a fluorescence microscope (Olympus FV300; Olympus, Tokyo, Japan) equipped with a CDD camera.

Flow cytometry. SKP-derived mesenchymal cells were detached by trypsinization, and aliquots of $1.0 \times 10^{6}$ cells were prepared in 5-ml round-bottom test tubes. After rinsing with PBS containing $0.2 \%$ FBS, cells were spun down and blocked with PBS containing $1 \%$ BSA and $0.2 \%$ FBS for $30 \mathrm{~min}$ at $4^{\circ} \mathrm{C}$. Cells were then incubated with primary antibodies to CD29 (1:10), CD44 (1:10), CD51 (1:10), CD73 (1:40), CD106 (1:7; BD Pharmingen, San Diego, CA, USA), and CD 133 (1:50) for $1 \mathrm{~h}$ on ice. After washing with PBS containing 0.2\% FBS, cells were incubated with FITC-labeled secondary antibodies for $1 \mathrm{~h}$ on ice. Finally, cells were analyzed on a FACSCalibur flow cytometer (Becton-Dickinson, Franklin Lakes, NJ, USA).

RT-PCR and quantitative real-time PCR. mRNA levels of specific marker genes were determined by RT-PCR. Total RNA was isolated using the TRI-reagent (Molecular Research Center, Cincinnati, OH, USA), according to the manufacturer's instructions. After the RNA was denatured by $70^{\circ} \mathrm{C}$ incubation for $10 \mathrm{~min}$ and kept on ice for $5 \mathrm{~min}$, cDNA was prepared using reverse transcriptase (Invitrogen) and a random hexamer and then subjected to PCR amplification of specific marker genes using a $300 \mathrm{nM}$ final concentration of each primer (Table I) and cDNA, corresponding to $133 \mathrm{ng}$ of total RNA. After incubation at $95^{\circ} \mathrm{C}$ for $2 \mathrm{~min}$, PCR cycling conditions consisted of 30 cycles at $95^{\circ} \mathrm{C}$ for $20 \mathrm{sec}, 60^{\circ} \mathrm{C}$ for $10 \mathrm{sec}$, and $70^{\circ} \mathrm{C}$ for $4 \mathrm{sec}$. Reaction products were analyzed by $1.5 \%$ agarose gel electrophoresis and visualized by ethidium bromide staining. In addition, real-time PCR was performed, using the 7500 Real-time PCR System (Applied Biosystems, Foster City, CA, USA). Primer sequences were designed using Primer Express $^{\circledR}$ Software version 3.0 (Applied Biosystems). The cDNA was prepared using reverse transcriptase and a random hexamer, and then subjected to real-time PCR amplification using SYBR ${ }^{\circledR}$ Green PCR Master Mix (Takara, Shiga, Japan) that contained a $300 \mathrm{nM}$ final concentration of each primer (Table I) and cDNA, corresponding to $33 \mathrm{ng}$ of total RNA. After incubation at $95^{\circ} \mathrm{C}$ for $4 \mathrm{~min}$, PCR cycling conditions consisted of 40 cycles at $95^{\circ} \mathrm{C}$ for $15 \mathrm{sec}, 60^{\circ} \mathrm{C}$ for $20 \mathrm{sec}$, and $72^{\circ} \mathrm{C}$ for $34 \mathrm{sec}$. To analyze the data, cycle threshold values were determined by automated threshold analysis with Sequenced Detection Software version 1.3, after which the calculated cycle threshold values were exported to Microsoft Excel for analysis. The relative expression of each target mRNA was calculated using the comparative cycle threshold method according to the manufacturer's procedures (Applied Biosystems).

Animal experiments. Twelve adult male Sprague-Dawley rats weighing 180-200 g (age: 6 weeks) were randomly divided into three groups of four: i) a vehicle (PBS)-loaded HA/TCP group as the negative control, ii) a SKP-derived, differentiated osteogenic cell-loaded HA/TCP group as the positive control, and iii) a SKP-derived MSC-loaded HA/TCP group. In order to prepare the mixture of scaffold and cells, $30 \mathrm{mg}$ of porous HA/ TCP (particle size of $\sim 0.8 \times 0.8 \mathrm{~mm}$ ) was incubated with $4.0 \times 10^{5}$ cells in $50 \mu \mathrm{l}$ PBS at room temperature for $2 \mathrm{~min}$ with constant stirring. For the calvarial defect model, the surgical site was shaved and scrubbed with iodine after anesthetizing by injecting a ketamine $(50 \mathrm{mg} / \mathrm{kg})$ and xylazine $(10 \mathrm{mg} / \mathrm{kg})$ mixture i.m. An incision was made in the sagittal plane across the cranium, and a full thickness flap was reflected to expose the calvarial bone. A standardized, circular, transosseous defect, $8 \mathrm{~mm}$ in diameter, was created on the cranium with a trephine bur (ACE Dental Implant System, Brockton, MA, USA) and was copiously irrigated with saline. After removal of the trephined calvarial disk, Beschitin $\mathrm{W}^{\circledR}$ matrices were cut out with a trephine bur (8 $\mathrm{mm}$ in diameter) and placed on defect sites. A mixture of HA/TCP and either SKP-derived, differentiated osteogenic cells or SKP-derived MSCs was transplanted into the calvarial defects. All surgical sites were sutured for primary closure with 4-0 Silkam ${ }^{\circledR}$ (Aesculap, Center Valley, PA, USA). The rats were sacrificed at 4 weeks post-surgery, and whole calvariae were fixed in $4 \%$ paraformaldehyde for $24 \mathrm{~h}$ at $4{ }^{\circ} \mathrm{C}$ and then analyzed using a micro-computed tomography (micro-CT) scanning (SkyScan 1172 high-resolution micro-CT, SkyScan, Kontich, Belgium). The specimens were then decalcified with $12 \%$ EDTA (pH 7.7) for 4 weeks and embedded in paraffin. Paraffin embedded samples were sectioned at $6 \mu \mathrm{m}$ and then stained with hematoxylin and eosin (H\&E) and Masson Trichrome.

Statistical evaluations. All experiments were performed at least in triplicate. Data are expressed as mean \pm SD. 
Table I. Primers for specific marker genes used to assess cell differentiation in RT-PCR and real-time PCR.

\begin{tabular}{|c|c|c|c|}
\hline Gene (NCBI ID) & Forward primer & Reverse primer & Product size (bp) \\
\hline $\begin{array}{l}\text { Peripherin } \\
\text { (NM_013639.1) }\end{array}$ & 5'-CCACTCTGTCCCGCCTAGAA-3' & 5'-TGCAGGTCTCGAAGTTCCTCTT-3' & 100 \\
\hline $\begin{array}{l}\text { TuJ1 (Tubb3) } \\
\text { (NM_023279.2) }\end{array}$ & 5'-TCCGCCTGCCTTTTCGTCTCTA-3' & 5'-AGTTGCCGCTGGGGTCTATGC-3' & 144 \\
\hline GFAP (NM_010277.2) & 5'-CATGCCACGCTTCTCCTTGTCTC-3' & 5'-GCTCGCTCGCCCGTGTCT-3' & 108 \\
\hline S100ß (NM_009115.3) & 5'-CCTTTCAGGATGATCGCTTTG-3' & 5'-ATGGACAGCAGAGGGAGCAA-3' & 100 \\
\hline ALP (NM_007433.3) & 5'-GTGCCCTGACTGAGGCTGTC-3' & 5'-GGATCATCGTGTCCTGCTCAC-3' & 81 \\
\hline $\begin{array}{l}\text { Bone sialoprotein } \\
\text { (NM_008318.1) }\end{array}$ & 5'-CACCCCAAGCACAGACTTTTG-3' & 5'-TCCTCGTCGCTTTCCTTCAC-3' & 100 \\
\hline $\begin{array}{l}\text { Osteocalcin } \\
\text { (NM_001032298.2) }\end{array}$ & 5'-CCGGGAGCAGTGTGAGCTTA-3' & 5'-TAGATGCGTTTGTAGGCGGTC-3' & 61 \\
\hline $\begin{array}{l}\text { Osteopontin } \\
\text { (NM_009263.1) }\end{array}$ & 5'-GATGCCACAGATGAGGACCTC-3' & 5'-CTGGGCAACAGGGATGACAT-3' & 81 \\
\hline $\begin{array}{l}\text { C/EBP } \alpha \\
\left(\mathrm{NM} \_007678.3\right)\end{array}$ & 5'-TCAGACCAGAAAGCTGAGTTGTG-3' & 5'-TGGTCCCCGTGTCCTCCTA-3' & 100 \\
\hline LPL (NM_008509.2) & 5'-CATCGAGAGGATCCGAGTGAA-3' & 5'-TGCTGAGTCCTTTCCCTTCTG-3' & 100 \\
\hline PPAR $\gamma$ (NM_011146.2) & 5'-AACTGCCGGATCCACAAAAA-3' & 5'-GCCCAAACCTGATGGCATT-3' & 100 \\
\hline ATF3 (NM_007498.3) & 5'-CCTCCTGGGTCACTGGTATTTG-3' & 5'-TCCGATGGCAGAGGTGTTTAT-3' & 100 \\
\hline $\begin{array}{l}\text { Collagen type II } \alpha 1 \\
(\mathrm{NM} \text {-031163.2) }\end{array}$ & 5'-CCGGCCCTCAAGGATTTCAA-3' & 5'-TCCCAGCTTCACCGTCGTCA-3' & 123 \\
\hline Ihh (NM_010544.2 & 5'-CTGCCCAGGCTAAGCTCCTT-3' & 5'-GATTTCCCCCTCCATGCAA-3' & 100 \\
\hline Sox5 (NM_011444.1) & 5'-AACAGTCCACCACCCAAAAGC-3' & 5'-AGGTGGGTGATGCAGGTGAT-3' & 100 \\
\hline SMA $\alpha$ (NM_007392.2) & 5'-CCAAАTCATTCCTGCCCAAA-3' & 5'-GTTGCTAGGCCAGGGCTACA-3' & 100 \\
\hline SMA $\gamma$ (NM_009610.2) & 5'-ССТСТTCCAGCCTTCCTTCA-3' & 5'-CAAATCTTTGCGGATGTCAATG-3' & 100 \\
\hline $\begin{array}{l}\text { Caldesmon } \\
\text { (NM_145575.3) }\end{array}$ & 5'-CCGCATTAACGAATGGCTAAC-3' & 5'-GTTCCGCTTGCCAGATACATC-3' & 100 \\
\hline $\begin{array}{l}\text { Smoothelin } \\
\text { (NM_013870.2) }\end{array}$ & 5'-CGCCCTCGCACGATTG-3' & 5'-CAGCTTGCGCTCCTCATATTC-3' & 100 \\
\hline $\begin{array}{l}\text { GAPDH } \\
\text { (NM_008084.2) }\end{array}$ & 5'-ATGACTCCACTCACGGCAAAT-3' & 5'-GGGTCTCGCTCCTGGAAGAT-3' & 100 \\
\hline
\end{tabular}

Differences between differentiated and undifferentiated SKPs or SKP-derived MSCs were evaluated with Student's t-tests. The statistical significance of the in vivo results was analyzed with a one-way ANOVA followed by Scheffe's adjustment. $\mathrm{P}<0.05$ was defined as statistically significance.

\section{Results}

SKPs can be derived from adult mouse skin. To isolate SKPs from adult mice skin, we adapted a technique devised to generate neural stem cells from the brain $(2,16,17)$. Skin samples composed of epidermis and dermis were dissociated from 6 to 7-week-old C57/BL6 mice $\left(\sim 1-2 \mathrm{~cm}^{2}\right)$ and cultured in defined medium containing EGF and bFGF2. Many cells adhered to the culture dishes and many died, but small spheres of floating cells formed within three days. The spheres were isolated, centrifuged, and separated into single cells with accutase treatment. These cells were transferred to a new flask seven days after initial culturing. Once again, many cells adhered, but cells in the floating spheres proliferated to generate larger spheres (Fig. 1A). The spheres were then isolated after seven days of culture, dissociated, and cultured in fresh medium supplemented with growth factors. Purified populations of floating spheres were obtained after three subcultures over three weeks using this process of selective adhesion (Fig. 1A). Each time, the spheres were dissociated to 
A

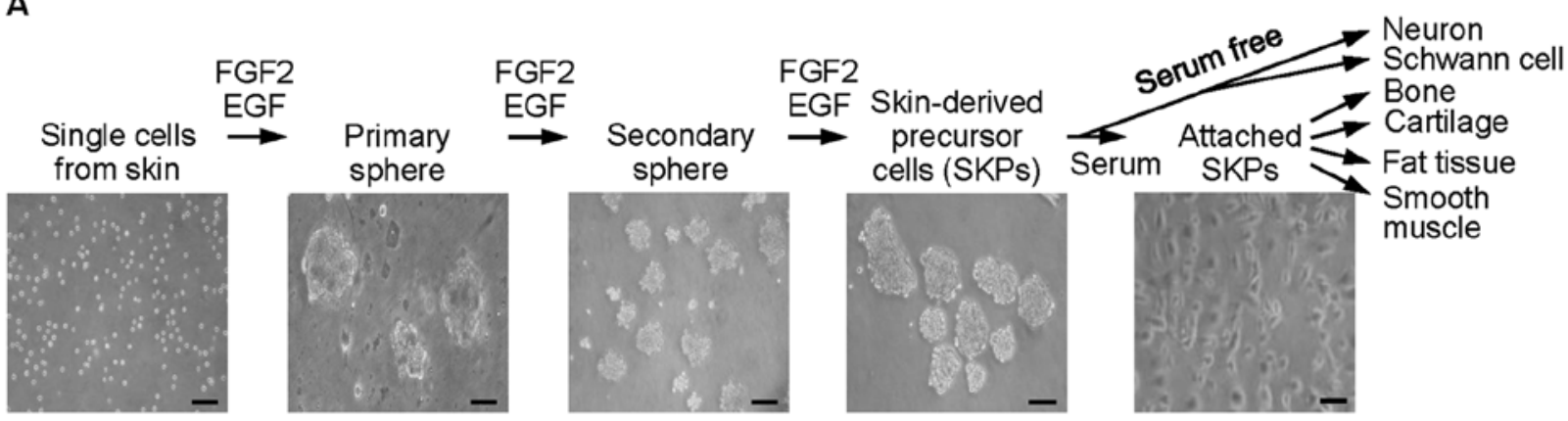

B

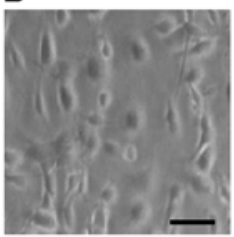

Attached SKPs

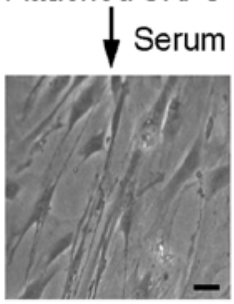

Mesenchymal cells
C

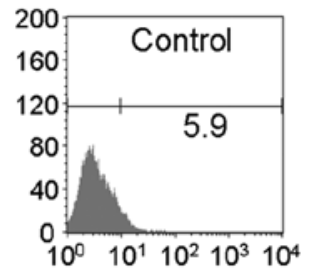

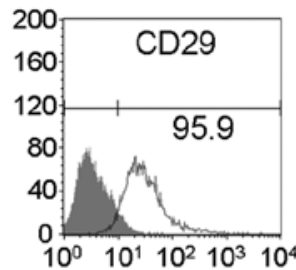
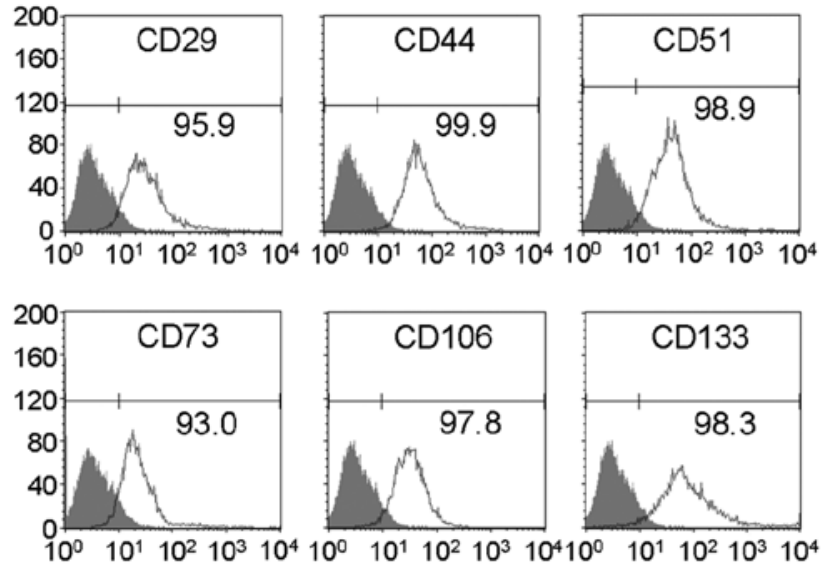

$\begin{array}{lllll}10^{0} & 10^{1} 10^{2} 10^{3} 10^{4} 10^{0} & 10^{1} 10^{2} 10^{3} 10^{4}\end{array}$

Figure 1. Stepwise isolation of SKPs from adult mouse skin and directed differentiation via extrinsic signals. (A) Schematic illustration of the experimenta design (upper) and representative images of sphere-forming SKPs (lower) following 7, 14, and 21 days of in vitro expansion. Following initial purification, SKPs that grew as spheres in suspension and were dissociated to single cells generated spheres again over the course of one week. Serum-free conditions allow differentiation of SKPs into both neurons, as well as Schwann cells. Serum exposure led to rapid conversion of SKP cultures into mesenchymal precursors Scale bars, $50 \mu \mathrm{m}$. (B) Morphology of the SKP-derived mesenchymal precursors upon exposure to serum-containing medium. Scale bars, $50 \mu \mathrm{m}$. (C) FACS analysis of the surface marker profile of SKP-derived mesenchymal precursors.

single cells when passaged, and subsequently proliferated to generate new spheres.

Mouse SKPs differentiate into MSCs. Since adult rat skin is known to contain MSCs, which contribute to the regeneration of mesenchymal tissues, such as bone, cartilage, muscle, ligament, tendon, adipose, and stroma (18-20), we looked for multipotent MSCs in adult mouse skin. After isolation and expansion of the mesenchymal cells from adult mouse skin taken from the back, we identified an isolated population of homogeneous mouse mesenchymal cells. The SKP-derived mesenchymal cells were characterized by their ability to proliferate in culture with an attached, well-spread morphology (Fig. 1B), by the presence of marker proteins on their surface (Fig. 1C), and by their extensive differentiation to multiple mesenchymal lineages under controlled in vitro conditions (Figs. 3-6). These expanded, attached SKP-derived mesenchymal cells were uniformly positive for many surface proteins, including CD29, CD44, CD51, CD73, CD106, and CD133 (Fig. 1C). These results indicate that mouse SKPs can differentiate into SKP-derived MSCs under the described culture conditions.

Directed differentiation of mouse SKPs toward peripheral nervous system lineages. To determine whether mouse SKPs could generate neural cell types, such as peripheral neurons and Schwann cells, mouse SKPs were plated on polyornithine/ laminin-coated dishes and cultured for two weeks in the presence of BDNF, NT3, and NGF (peripheral neurons) or dbcAMP, bFGF, and neuregulin (Schwann cells). After two weeks, a subpopulation of differentiated cells with neuronal morphology coexpressed the pan-neuronal marker TuJ1 and peripherin, a protein typical of peripheral neurons (7) (Fig. 2A). Real-time PCR and RT-PCR analysis revealed that mouse SKPs generated cells producing TuJ1 and peripherin at two weeks after plating (Fig. 2B and E). Since the neural cell types of interest were largely peripheral cells that derive from the neural crest during development (9), we further addressed whether mouse SKPs could differentiate into Schwann cells. SKP-derived Schwann cells were identified in vitro by immunocytochemical markers specific to Schwann cells, such as S100 $\beta$ and GFAP (10). Immunostaining (Fig. 2C), real-time PCR (Fig. 2D), and RT-PCR analysis (Fig. 2F) revealed that mouse SKPs generated cells that expressed Schwann cell markers. Double-labeling for S100 $\beta$ and GFAP demonstrated that a subpopulation of S100 $\beta$ positive cells also coexpressed GFAP (Fig. 2B), indicating that those cells were likely to be Schwann cells. After 2 weeks in lineage-specific culture conditions, the majority ( $>95 \%)$ of the expanded cells were stained by immunocytochemical markers specific to peripheral neurons and Schwann cells, respectively (data not shown). Taken together, these results indicate that 
A
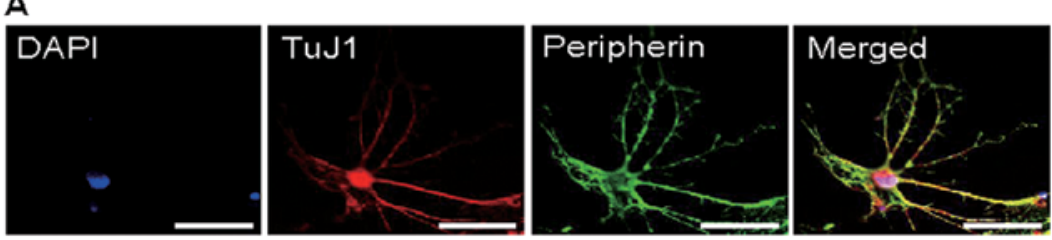

C
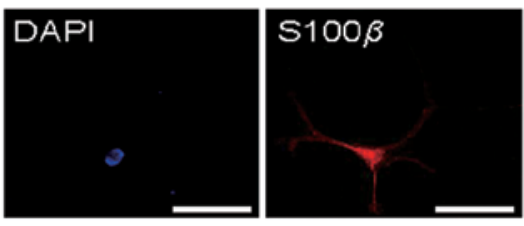

E

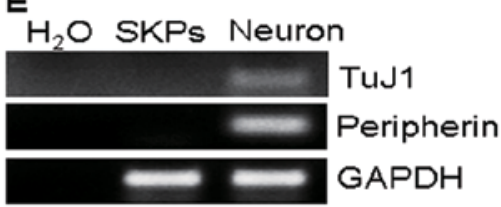

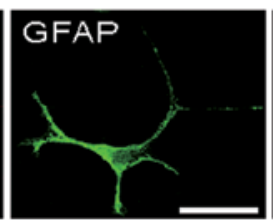

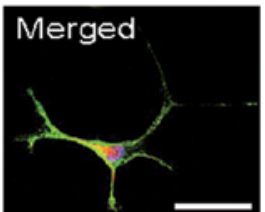

$\mathbf{F}$

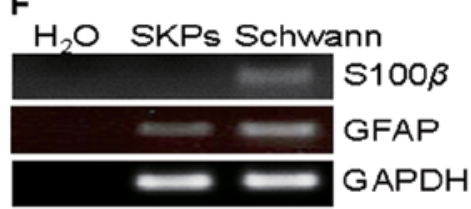

B
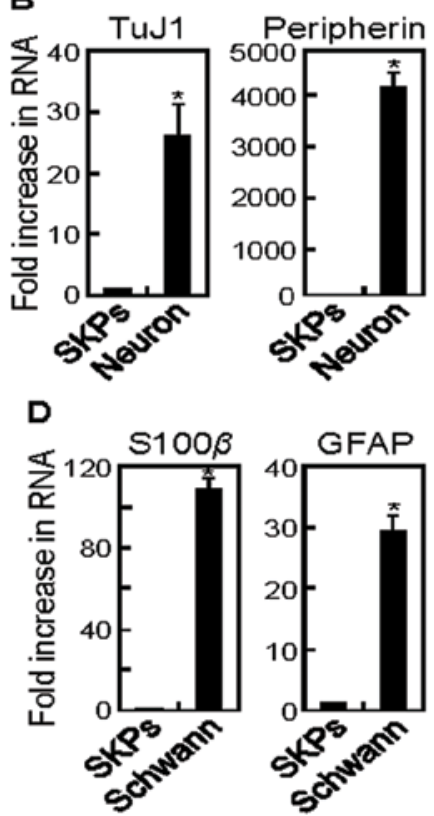

Figure 2. Differentiation of mouse SKPs toward peripheral nervous system lineages. Representative images of differentiated SKPs stained with markers for peripheral neurons (A) and Schwann cells (C). Peripheral neurons were double-labeled for TuJ1 with peripherin. Schwann cells were double-labeled for S100 $\beta$ with GFAP. The yellow in the merged images denotes a cluster of cells positive for both markers, with nuclei stained blue (DAPI). Scale bars $=50 \mu \mathrm{m}$. Realtime PCR for specific marker genes of peripheral neurons (B) and Schwann cells (D) in total RNA isolated from both cells, as compared with SKPs. Data are expressed as the mean $\pm \mathrm{SD}$; "P<0.01. RT-PCR for specific marker genes of peripheral neurons (E) and Schwann cells (F). RT-PCR for GAPDH was used as a loading control, and a reaction without input nucleic acid was run in the first lane as a negative control.

A

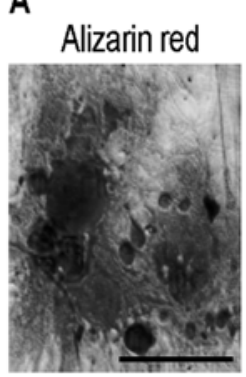

C

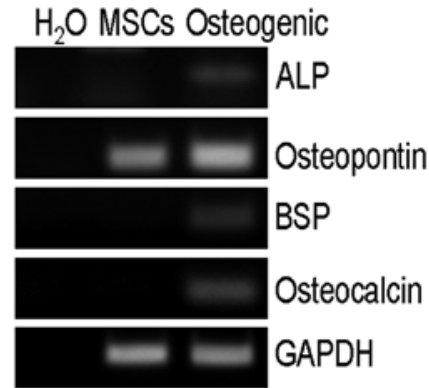

B

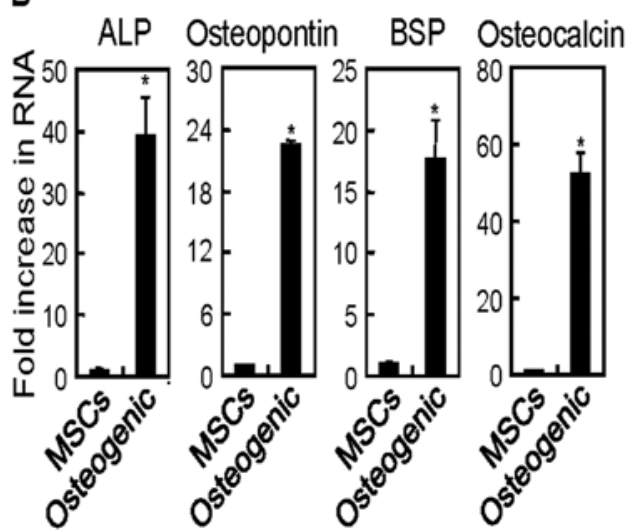

Figure 3. Characterization of osteogenic cells selectively induced from mouse SKP-derived MSCs. Photograph of monolayer cultures of SKPderived MSCs differentiated for two weeks under osteogenic conditions and then stained for mineral deposits using alizarin red (A). Scale bar, $50 \mu \mathrm{m}$. Expression of osteogenic markers, including alkaline phosphatase (ALP), osteopontin, bone sialoprotein (BSP), and osteocalcin was measured by realtime PCR (B) and RT-PCR analysis (C). RT-PCR for GAPDH was used as a loading control, and a reaction without input nucleic acid was run in the first lane as a negative control. Data are expressed as the mean $\pm \mathrm{SD}$; ${ }^{*} \mathrm{P}<0.01$. mouse SKPs can differentiate into peripheral neurons and Schwann cells.

Directed differentiation of mouse SKP-derived MSCs toward mesenchymally-derived cell types. Rodent SKPs are known to differentiate into both neural and mesodermal cell types, including neurons, glia, smooth muscle cells, and adipocytes (12). To examine the differentiation potential toward mesenchymal lineages of SKP-derived MSCs, we cultured SKP-derived MSCs (passage 3) under modified conditions, as previously described (15). The cells that differentiated toward osteogenic, chondrogenic, adipogenic, or smooth muscle cells from the SKP-derived MSCs were compared to undifferentiated SKP-derived MSCs. After 2-6 weeks in lineage-specific culture conditions, the expanded cells were highly differentiated into lineage-specific cell types (Figs. 3-6).

Osteogenic differentiation was induced in the SKP-derived mesenchymal cell cultures by treatment with $\beta$-glycerol phosphate, dexamethasone, and ascorbic acid in the presence of $10 \%$ FBS. The differentiated osteogenic cells formed aggregates or nodules, and calcium accumulation was evident after two weeks. Alizarin red staining demonstrated mineral deposits associated with some of these nodules. These mineral deposits were abundant at two weeks and localized both to cells in the nodules and to some that grew in monolayers (Fig. 3A). Realtime PCR analysis revealed an $\sim 40$-fold increase in alkaline phosphatase (ALP) gene expression (Fig. 3B). Next, we assessed the expression of osteogenic-specific marker genes, including bone sialoprotein (BSP), osteocalcin, and osteopontin. Samples of SKP-derived MSCs and the differentiated osteogenic cells were evaluated by real-time PCR analysis with various primers (Table I). Previous studies have reported that osteonectin, type 
A

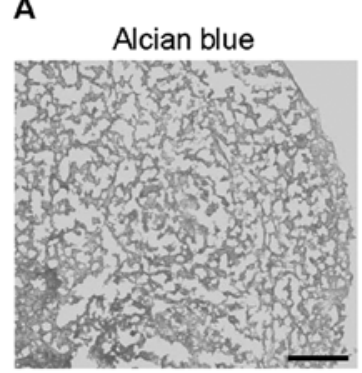

C

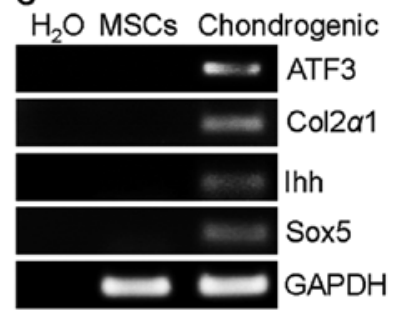

B
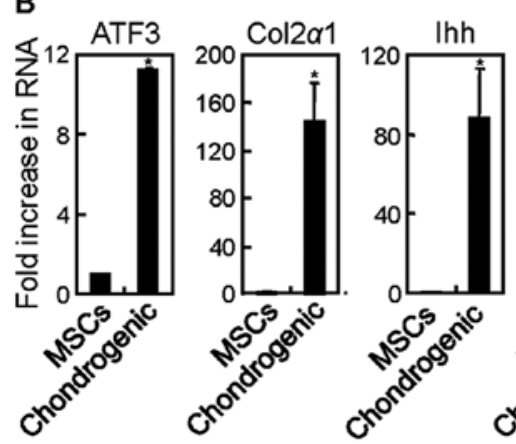

Sox5

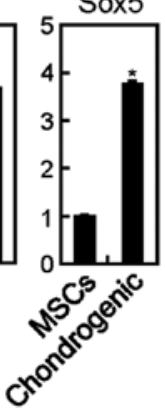

Figure 4. Characterization of chondrogenic cells selectively induced from mouse SKP-derived MSCs. Photograph of micromass cultures of mouse SKPs differentiated for four weeks under chondrogenic conditions and then stained with alcian blue (A). Scale bar, $100 \mu \mathrm{m}$. Expression of chondrogenic markers, including activating transcription factor 3 (ATF3), collagen type II $\alpha 1$ (Col2 $\alpha 1)$, Indian hedgehog (Ihh), and SRY-box containing gene 5 (Sox5) was measured by real-time PCR (B) and RT-PCR analysis (C). RT-PCR for GAPDH was used as a loading control, and a reaction without input nucleic acid was run in the first lane as a negative control. Data are expressed as the mean $\pm \mathrm{SD} ;{ }^{*} \mathrm{P}<0.01$.

I collagen, and osteopontin are early/intermediate markers for osteogenesis, while Cbfa-1, BSP, and osteocalcin are intermediate/late markers (21). We found that the expression level of osteopontin was significantly higher in the differentiated osteogenic cells, as compared with the SKP-derived MSCs. The transcription of intermediate/late markers, including BSP and osteocalcin, was also upregulated in the differentiated osteogenic cells (Fig. 3B). We further confirmed the expression levels of osteogenic-specific marker genes via RT-PCR. The expression levels of osteogenic-specific marker genes were very similar to the results of real-time PCR analysis (Fig. 3C). Taken together, these results indicate that SKP-derived MSCs can differentiate into an osteogenic lineage.

To induce chondrogenic differentiation, we gently centrifuged the SKP-derived MSCs to form a pelleted micromass and cultured the cells with TGF- $\beta$ and ascorbic acid in the presence of $10 \%$ FBS. After 4 weeks of chondrogenic differentiation, cell pellets were fixed, embedded, cut in $5-\mu \mathrm{m}$ thick sections, and stained with the chondrocytic marker alcian blue 8GX. The cell pellets stained positive for alcian blue (Fig. 4A) and developed a multilayered matrix-rich morphology after four weeks of chondrogenic differentiation. In addition, chondrocyte-like lacunae were evident in histological sections. Real-time PCR (Fig. 4B) and RT-PCR results (Fig. 4C) showed that differentiated chondrogenic cells expressed chondrogenicspecific marker genes, such as activating transcription factor 3 (ATF3), collagen type II $\alpha 1$ (Col2 $\alpha 1)$, Indian hedgehog (Ihh), and SRY-box containing gene 5 (Sox5). Overall, these results
A

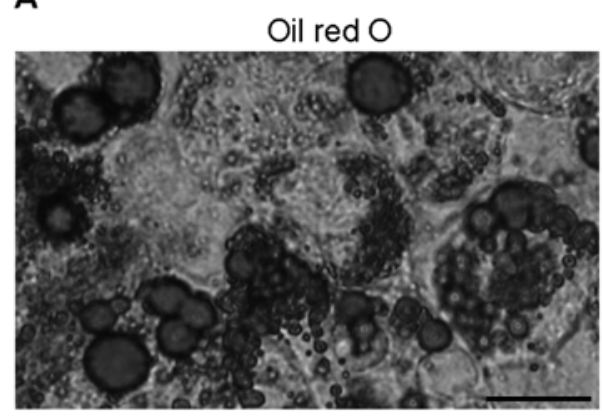

B
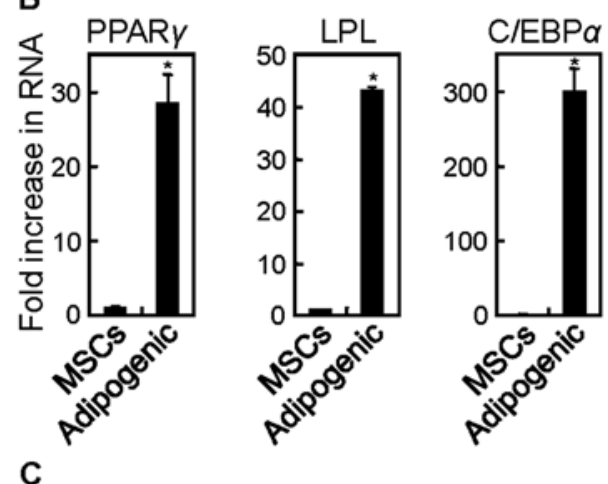

$\mathrm{H}_{2} \mathrm{O}$ MSCs Adipogenic

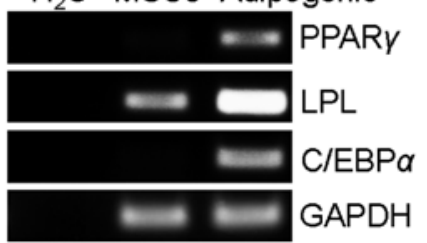

Figure 5. Characterization of adipogenic cells selectively induced from mouse SKP-derived MSCs. Photograph of monolayer cultures of SKPderived MSCs differentiated for four weeks under adipogenic conditions and then stained with oil red O (A). Scale bar, $100 \mu \mathrm{m}$. Expression of adipogenic markers, including peroxisome proliferation-activated receptor $\gamma(\operatorname{PPAR} \gamma)$, lipoprotein lipase (LPL), and CCAAT/enhancer binding protein $\alpha(\mathrm{C} / \mathrm{EBP} \alpha)$ was measured by real-time PCR (B) and RT-PCR analysis (C). RT-PCR for GAPDH was used as a loading control, and a reaction without input nucleic acid was run in the first lane as a negative control. Data are expressed as the mean $\pm \mathrm{SD} ;{ }^{*} \mathrm{P}<0.01$.

indicate that SKP-derived MSCs can differentiate into a chondrogenic lineage.

Adipogenic differentiation was induced in the SKP-derived mesenchymal cell cultures by treatment with dexamethasone, insulin, indomethacin, and 1-methyl-3-isobutylxanthine for four weeks. Induction was apparent by the accumulation of lipid-rich vacuoles within cells (Fig. 5A). After 2-3 weeks of adipogenic incubation, cytoplasmic lipid vesicles characteristic of differentiated adipocytes formed. The cytoplasmic lipid vesicles were apparent by the accumulation of lipid-rich vacuoles within cells. These adipocytes expressed fat cell-specific marker genes, such as peroxisome proliferation-activated receptor $\gamma$ $(\operatorname{PPAR} \gamma)$, lipoprotein lipase (LPL), and CCAAT/enhancer binding protein $\alpha(\mathrm{C} / \mathrm{EBP} \alpha$; Fig. 5B and $\mathrm{C})$. Multiple induction treatments resulted in $>95 \%$ of the cells committing to this lineage, and the lipid vacuoles continued to develop over time, coalesced, and eventually filled the cells. These results indicate that SKP-derived MSCs possess the ability to differentiate into adipogenic cells. 
A

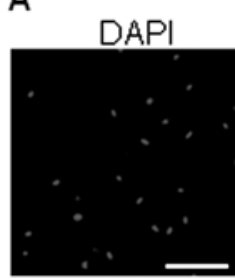

DAPI

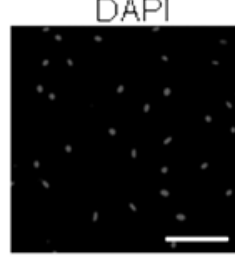

B

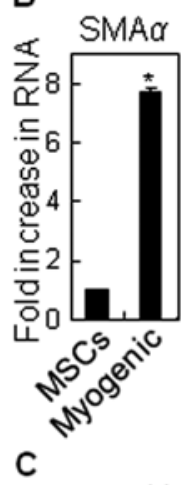

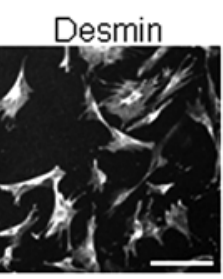

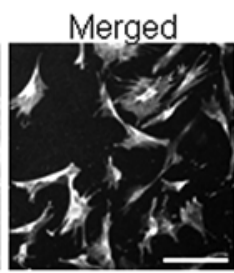

SMAO

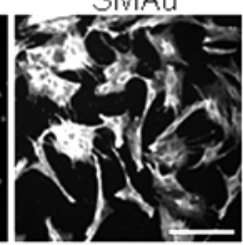

Merged

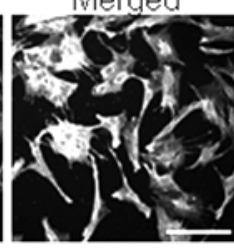

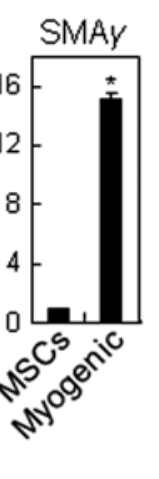

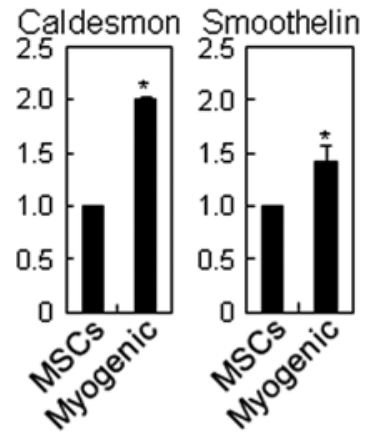

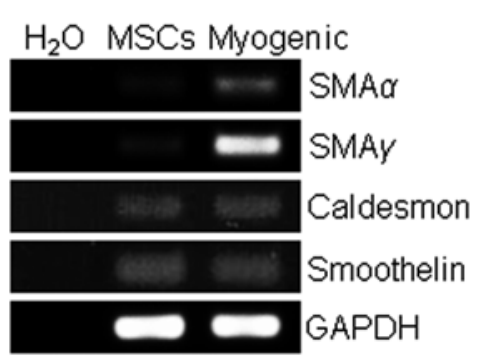

Figure 6. Characterization of smooth muscle cells selectively induced from mouse SKP-derived MSCs. Representative images of differentiated SKPs stained with the markers for smooth muscle cells (A). Differentiated smooth muscle cells were labeled for desmin and smooth muscle actin $\alpha$ (SMA $\alpha$ ). Nuclei are stained blue (DAPI). Scale bars, $200 \mu \mathrm{m}$. Expression of smooth muscle cell markers, including SMA $\alpha$, SMA $\gamma$, caldesmon, and smoothelin was measured by real-time PCR (B) and RT-PCR analysis (C). RT-PCR for GAPDH was used as a loading control, and a reaction without input nucleic acid was run in the first lane as a negative control. Data are expressed as the mean $\pm \mathrm{SD} ;{ }^{*} \mathrm{P}<0.01$.

To induce myogenic differentiation, $\sim 80 \%$ confluent SKP-derived MSCs (passage 3) were subsequently passaged by trypsinization (split ratio 1:3) to the nineteenth passage for 6 weeks. By passage 20, smooth muscle cell differentiation was assessed by cell morphology and immunocytochemistry. These cells were strongly positive for specific smooth muscle cell markers, such as desmin and SMA $\alpha$ (Fig. 6A). Using real-time PCR analysis, we found that the expression levels of specific smooth muscle cell marker genes, such as SMA $\alpha, \mathrm{SMA} \gamma$, caldesmon, and smoothelin, were higher in the differentiated smooth muscle cells, as compared with the SKP-derived MSCs (Fig. 6B). We further confirmed the expression levels of specific smooth muscle cell marker genes via RT-PCR. The expression levels of specific smooth muscle cell marker genes were very

similar to the results of real-time PCR analysis (Fig. 6C). These results indicate that SKP-derived MSCs possess the ability to differentiate into smooth muscle cells.

Transplanted SKP-derived MSCs promote new bone formation. To investigate the effect of SKP-derived MSCs on osteogenic capacity to repair bone defects in vivo, a rat critical-sized calvarial defect model was utilized. Micro-CT images of calvarial defects demonstrated that bone volume was increased $~ 1.4-$ and 2.0-fold in the SKP-derived, differentiated osteogenic cell- and the SKP-derived MSC-loaded HA/TCP groups compared to vehicle-loaded control group, respectively (Fig. 7A). H\&E staining showed that there was no new osteoid tissue formation in the vehicle-loaded HA/TCP group, although fibrosis and infiltration of giant cells were observed (Fig. 7B, left panel). In the SKP-derived, differentiated osteogenic cell- and the SKP-derived MSC-loaded HA/ TCP groups, we observed distinct and widespread formation of immature bone tissue around the transplanted HA/TCP. Similarly, evidence of fibrosis or infiltration of giant cells was also observed in these groups (Fig. 7B, right panel). To detect collagen deposition in the transplanted site, we used Masson Trichrome staining. Masson Trichrome-stained histological sections confirmed greater amounts of bone regeneration in the SKP-derived, differentiated osteogenic cell- and the SKP-derived MSC-loaded HA/TCP groups, compared to vehicle-loaded control group, respectively (Fig. 7C). In addition, we did not observe any formation of teratomas or tumors in the sacrificed rats.

\section{Discussion}

Although previous evidence has shown that SKPs are multipotent dermal precursors that share similarities with NCSCs $(6,7)$, a shared ability for multilineage differentiation toward neural crest lineages has not been fully demonstrated. Accordingly, we examined whether SKPs could differentiate toward neural crest lineages in vitro. We found that adult mouse SKPs displayed multipotency by showing directed differentiation into peripheral nervous system lineages, such as peripheral neurons and Schwann cells, and mesenchymal lineages, such as smooth muscle, adipogenic, osteogenic, and chondrogenic cells, via extrinsic signals. Since NCSCs derived from human embryonic stem cells are capable of multilineage differentiation toward neural crest lineages in vitro (15), our findings support the possibility that SKPs display a similar differentiation potential. These results are consistent with previous studies $(2,7,15)$ that isolated SKPs share characteristics with NCSCs in microarray and clonal analyses.

SKPs are known to reside within a hair follicle niche and have properties similar to embryonic NCSCs, including the transcription factors they express, their migration when placed into the neural crest migratory stream in embryonic chicks, and their differentiation potential $(7,8)$. Most previous studies with SKPs have shown, in parts, their differentiation into peripheral neural cells, including Schwann cells $(9,10)$ and catecholaminergic neurons, or mesenchymally-derived cell types $(2,6,12)$. These findings suggest that SKPs may differentiate into neural crest lineages, based upon their ability to 
A

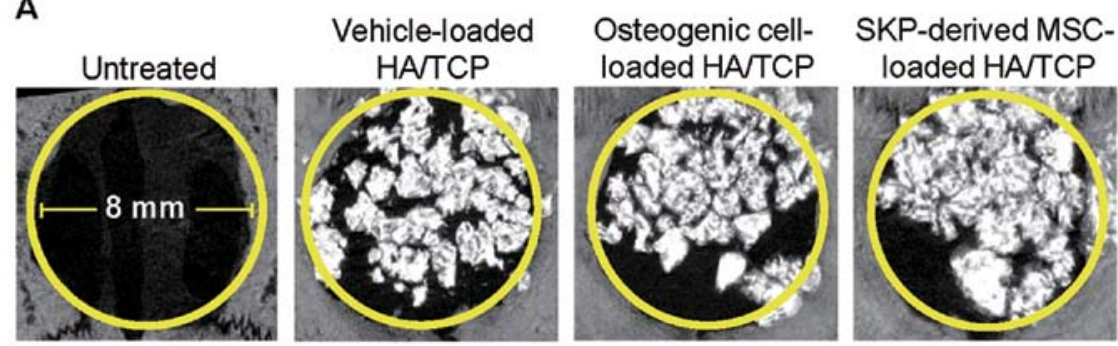

B
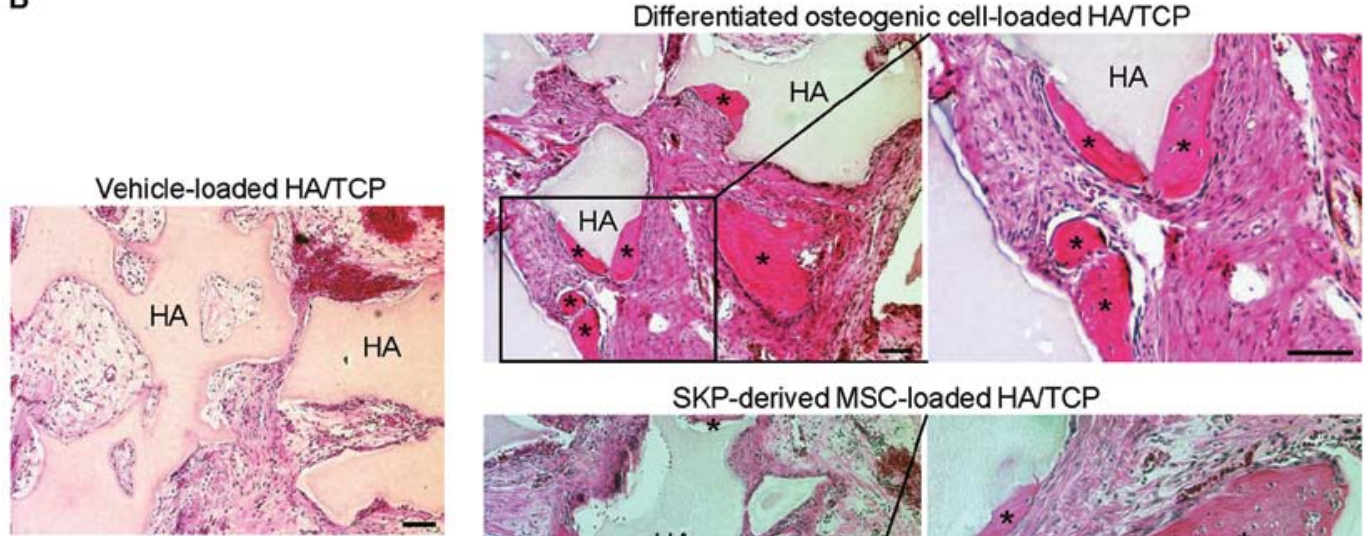

SKP-derived MSC-loaded HATTCP
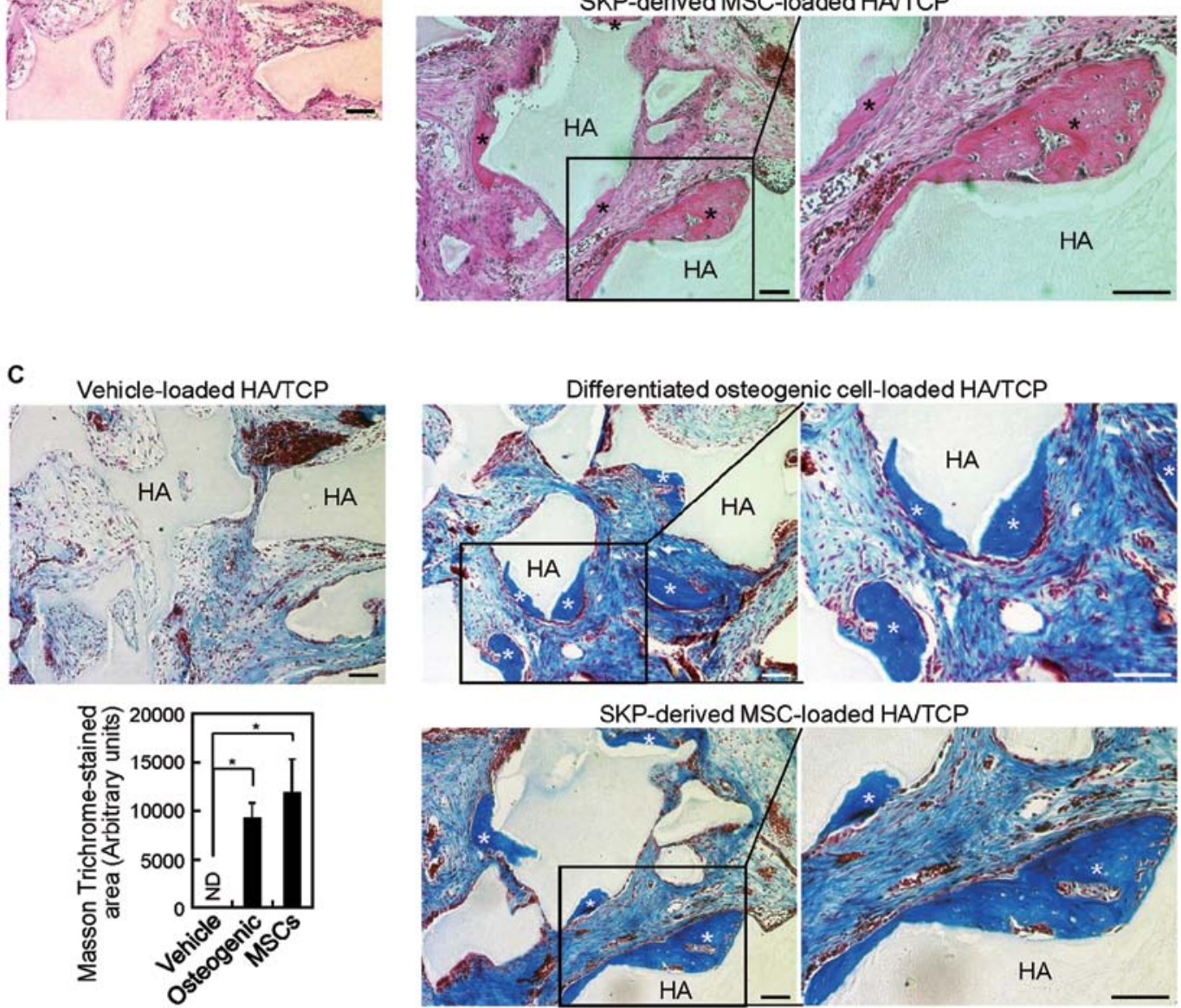

SKP-derived MSC-loaded HA/TCP

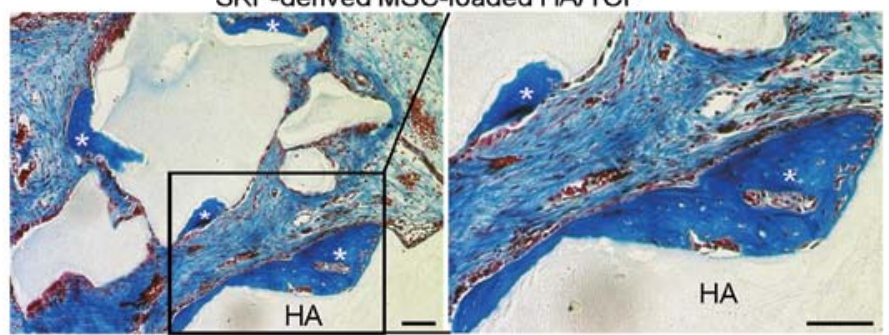

Figure 7. Effect of transplanted SKP-derived MSCs on in vivo bone regeneration. Critical size rat calvarial defects were implanted with absorbable HA/ TCP treated with vehicle (PBS), SKP-derived, differentiated osteogenic cells, or SKP-derived MSCs (4.0x10 $0^{5}$ cells/30 mg HA/TCP) at room temperature for 2 min with constant stirring. (A) Micro-CT images of calvarial defects, which were implanted with HA/TCP treated with vehicle, SKP-derived, differentiated osteogenic cells, and SKP-derived MSCs. (B) H\&E staining of HA/TCP treated with vehicle, SKP-derived, differentiated osteogenic cells, and SKP-derived MSCs. HA stands for the HA/TCP regions. The asterisks show the location of the newly formed bone structure. Boxed area was enlarged in the left panel. Scale bars, $100 \mu \mathrm{m}$. (C) Masson Trichrome staining for collagen in each group. The blue areas (asterisks) show the deposition of collagen. Boxed area was enlarged in the left panel. Scale bars, $100 \mu \mathrm{m}$. ND, not detected. Values are expressed as the mean $\pm \mathrm{SD} ;(\mathrm{n}=4),{ }^{*} \mathrm{P}<0.01$.

generate neural crest derivatives, but the multilineage differentiation potential toward neural crest lineages in vitro remains unknown. Rodent and human SKPs can differentiate into osteocytes and chondrocytes in culture, based on immunohistochemistry and histological staining (6). In this study, we described the isolation of SKPs from adult mouse skin and 
showed that SKPs can efficiently differentiate into neural crest lineages via extrinsic signals, as determined by flow cytometry, immunohistochemistry, histological staining methods, quantitative real-time PCR, and RT-PCR. These findings expand our conception of the differentiation potential of SKPs.

The isolation and directed differentiation of SKPs derived from adult mouse skin can be routinely performed from small pieces of skin. We also showed that SKPs can generate primary, secondary, and tertiary floating sphere structures in vitro, similar to those produced by primary NCSCs and human embryonic stem cell-derived NCSCs $(15,22)$. In this study, mouse SKPs differentiated into peripheral neurons and Schwann cells under controlled serum-free conditions in vitro. These results are consistent with previous reports $(7,9,10,12)$ and indicate that SKPs differentiate into peripheral neurons and Schwann cells. Moreover, our cultures of expanded mesenchymal cells from mouse SKPs appeared to progress to the mesenchymal lineage (adipogenic, chondrogenic, osteogenic, and smooth muscle cells). Numerous studies have described molecular signals related to the induction of peripheral nervous system lineages $(7,9,10,12)$ and mesenchymal lineages (15,23-29). Expression of marker proteins on their surface and differentiation potential toward peripheral nervous system lineages and mesenchymal lineages suggest the presence of NCSC precursors in adult mouse SKPs cultures. However, our study does not indicate that a single SKP cell can give rise to both neural and mesenchymal progeny.

These findings raise the potential for the therapeutic use of multipotent adult precursors like SKPs and SKP-derived MSCs. SKPs can generate large numbers of myelinating Schwann cells (9), and these SKP-derived Schwann cells promote functional recovery when transplanted into the contused rodent spinal cord (30). SKPs represent an accessible adult source of neural precursors for treating the damaged nervous system (12). Likewise, adult stem cells, such as bone marrow stem cells, MSCs, or SKPs, have been reported to have differentiation potential toward osteogenic tissues when transplanted with biomaterials or scaffolding materials, such as alginate, HA, hydrogel, and matrigel (6,31-33). In this study, we transplanted SKP-derived MSCs mixed with HA/TCP into the rat calvarial defects, and found that the SKP-derived MSCs could differentiate into osteogenic structures without teratoma formation. Moreover, the SKP-derived MSCs could form osteoid structures independent of biomaterials (HA/TCP). The mechanism or source of possible signals for that environment, however, has yet to be elucidated. SKP-derived MSCs appear to represent an accessible, potentially autologous source of precursor cells for use in regenerative medicine.

In conclusion, our findings demonstrate the multipotency of adult mouse SKPs toward neural crest lineages under controlled in vitro conditions, and a close similarity for multilineage differentiation between SKPs and NCSCs. In addition, SKP-derived MSCs may offer an alternative source for therapeutic applications.

\section{Acknowledgements}

We thank Dr Gabsang Lee for his critical comments and suggestions. This work was supported by Mid-career Researcher Program through NRF grant funded by the MEST
(2010-0014662), NRF grant funded by the MEST through the Bone Metabolism Research Center (2011-0001023), and Korea Research Foundation (313-2007-2-E00494).

\section{References}

1. Joseph NM and Morrison SJ: Toward an understanding of the physiological function of Mammalian stem cells. Dev Cell 9: 173-183, 2005.

2. Toma JG, Akhavan M, Fernandes KJ, et al: Isolation of multipotent adult stem cells from the dermis of mammalian skin. Nat Cell Biol 3: 778-784, 2001.

3. Jiang Y, Jahagirdar BN, Reinhardt RL, et al: Pluripotency of mesenchymal stem cells derived from adult marrow. Nature 418: 41-49, 2002.

4. Dicker A, Le Blanc K, Astrom G, et al: Functional studies of mesenchymal stem cells derived from adult human adipose tissue. Exp Cell Res 308: 283-290, 2005.

5. Joshi CV and Enver T: Plasticity revisited. Curr Opin Cell Biol 14: 749-755, 2002.

6. Lavoie JF, Biernaskie JA, Chen Y, et al: Skin-derived precursors differentiate into skeletogenic cell types and contribute to bone repair. Stem Cells Dev 18: 893-906, 2009.

7. Fernandes KJ, McKenzie IA, Mill P, et al: A dermal niche for multipotent adult skin-derived precursor cells. Nat Cell Biol 6: 1082-1093, 2004.

8. Wong CE, Paratore C, Dours-Zimmermann MT, et al: Neural crest-derived cells with stem cell features can be traced back to multiple lineages in the adult skin. J Cell Biol 175: 1005-1015, 2006.

9. McKenzie IA, Biernaskie J, Toma JG, Midha R and Miller FD: Skin-derived precursors generate myelinating Schwann cells for the injured and dysmyelinated nervous system. J Neurosci 26: 6651-6660, 2006.

10. Biernaskie JA, McKenzie IA, Toma JG and Miller FD: Isolation of skin-derived precursors (SKPs) and differentiation and enrichment of their Schwann cell progeny. Nat Protoc 1: 2803-2812, 2006.

11. Fernandes KJ, Kobayashi NR, Gallagher CJ, et al: Analysis of the neurogenic potential of multipotent skin-derived precursors. Exp Neurol 201: 32-48, 2006.

12. Toma JG, McKenzie IA, Bagli D and Miller FD: Isolation and characterization of multipotent skin-derived precursors from human skin. Stem Cells 23: 727-737, 2005.

13. Le Douarin NM, Creuzet S, Couly G and Dupin E: Neural crest cell plasticity and its limits. Development 131: 4637-4650, 2004.

14. Takashima Y, Era T, Nakao K, et al: Neuroepithelial cells supply an initial transient wave of MSC differentiation. Cell 129: 1377-1388, 2007.

15. Lee G, Kim H, Elkabetz Y, et al: Isolation and directed differentiation of neural crest stem cells derived from human embryonic stem cells. Nat Biotechnol 25: 1468-1475, 2007.

16. Reynolds BA and Weiss S: Generation of neurons and astrocytes from isolated cells of the adult mammalian central nervous system. Science 255: 1707-1710, 1992.

17. Reynolds BA, Tetzlaff $\mathrm{W}$ and Weiss S: A multipotent EGF-responsive striatal embryonic progenitor cell produces neurons and astrocytes. J Neurosci 12: 4565-4574, 1992.

18. Prockop DJ: Marrow stromal cells as stem cells for nonhematopoietic tissues. Science 276: 71-74, 1997.

19. Friedenstein AJ, Chailakhyan RK and Gerasimov UV: Bone marrow osteogenic stem cells: in vitro cultivation and transplantation in diffusion chambers. Cell Tissue Kinet 20: 263-272, 1987.

20. Haynesworth SE, Goshima J, Goldberg VM and Caplan AI: Characterization of cells with osteogenic potential from human marrow. Bone 13: 81-88, 1992.

21. zur Nieden NI, Price FD, Davis LA, Everitt RE and Rancourt DE: Gene profiling on mixed embryonic stem cell populations reveals a biphasic role for beta-catenin in osteogenic differentiation. Mol Endocrinol 21: 674-685, 2007.

22. Molofsky AV, Pardal R, Iwashita T, Park IK, Clarke MF and Morrison SJ: Bmi-1 dependence distinguishes neural stem cell self-renewal from progenitor proliferation. Nature 425: 962-967, 2003.

23. Pittenger MF, Mackay AM, Beck SC, et al: Multilineage potential of adult human mesenchymal stem cells. Science 284: 143-147, 1999. 
24. Kang HK, Roh S, Lee G, Hong SD, Kang H and Min BM Osteogenic potential of embryonic stem cells in tooth sockets. Int J Mol Med 21: 539-544, 2008.

25. Schilling T, Noth U, Klein-Hitpass L, Jakob F and Schutze N: Plasticity in adipogenesis and osteogenesis of human mesenchymal stem cells. Mol Cell Endocrinol 271: 1-17, 2007.

26. Ramirez-Zacarias JL, Castro-Munozledo F and Kuri-Harcuch W: Quantitation of adipose conversion and triglycerides by staining intracytoplasmic lipids with Oil red O. Histochemistry 97: 493-497, 1992.

27. Rodriguez LV, Alfonso Z, Zhang R, Leung J, Wu B and Ignarro LJ: Clonogenic multipotent stem cells in human adipose tissue differentiate into functional smooth muscle cells. Proc Natl Acad Sci USA 103: 12167-12172, 2006.

28. Bosnakovski D, Mizuno M, Kim G, et al: Chondrogenic differentiation of bovine bone marrow mesenchymal stem cells in pellet cultural system. Exp Hematol 32: 502-509, 2004.

29. Bursell L, Woods A, James CG, Pala D, Leask A and Beier F: Src kinase inhibition promotes the hondrocyte phenotype. Arthritis Res Ther 9: R105, 2007.
30. Biernaskie J, Sparling JS, Liu J, et al: Skin-derived precursors generate myelinating Schwann cells that promote remyelination and functional recovery after contusion spinal cord injury. J Neurosci 27: 9545-9559, 2007.

31. Weber M, Steinert A, Jork A, et al: Formation of cartilage matrix proteins by BMP-transfected murine mesenchymal stem cells encapsulated in a novel class of alginates. Biomaterials 23: 2003-2013, 2002

32. Boo JS, Yamada Y, Okazaki Y, et al: Tissue-engineered bone using mesenchymal stem cells and a biodegradable scaffold. J Craniofac Surg 13: 231-243, 2002.

33. Endres M,Hutmacher DW, Salgado AJ, et al: Osteogenic induction of human bone marrow-derived mesenchymal progenitor cells in novel synthetic polymer-hydrogel matrices. Tissue Eng 9: 689-702, 2003 